\title{
Lung metastasectomy following kidney tumors: outcomes and prognostic factors from a single-center experience
}

\author{
Elisa Meacci, Dania Nachira, Maria Teresa Congedo, Venanzio Porziella, Marco Chiappetta, Gianmaria \\ Ferretti, Amedeo Iaffaldano, Leonardo Petracca Ciavarella, Stefano Margaritora
}

Department of General Thoracic Surgery, A. Gemelli University Hospital, Catholic University of Sacred Heart of Rome, Rome, Italy

Contributions: (I) Conception and design: E Meacci, D Nachira; (II) Administrative support: S Margaritora; (III) Provision of study materials or patients: V Porziella, M Chiappetta; (IV) Collection and assembly of data: G Ferretti, A Iaffaldano, LP Ciavarella; (V) Data analysis and interpretation: D Nachira, E Meacci, MT Congedo; (VI) Manuscript writing: All authors; (VII) Final approval of manuscript: All authors.

Correspondence to: Elisa Meacci, MD. Department of General Thoracic Surgery, A. Gemelli University Hospital, Largo A. Gemelli 8, Rome 00167, Italy. Email: elisa.meacci@unicatt.it.

\begin{abstract}
Background: The lung is one of the sites most frequently affected by metastatic renal cell carcinoma (mRCC). Nonsurgical therapy for mRCC has limited efficacy, while the 5-year survival rates data published in literature after pulmonary surgery for metastasectomy, emphasize the role of surgery as the treatment that guarantees the best effectiveness in pulmonary resectable metastases.

Methods: From January 2000 to March 2016, 27 patients underwent pulmonary metastasectomy for metastatic renal cancer was retrospectively reviewed. Primary renal cancer was controlled in all patients and there was no other metastatic site in addition to the lung, at the time of metastasectomy. The aim of the study was to identify outcomes and prognostic factors in association with survival after complete pulmonary resection of metastases in a subgroup of patients with isolated pulmonary metastases from RCC.

Results: Five- and 10-year overall survival (OS) from first pulmonary metastasectomy was 75\% and 59\%, respectively. Independent prognostic factor influencing survival were: dimension of pulmonary metastases $\geq 2 \mathrm{~cm}$ (3-year survival: $67 \%$ vs. 100\%; $\mathrm{P}=0.014$ ) and disease free interval (DFI) $\geq 5$ years (3-year survival: $94 \%$ vs. $28 \% ; \mathrm{P}=0.05)$. The only independent prognostic factors affecting DFI was the dimension of pulmonary metastases $\geq 2 \mathrm{~cm}(5$-year DFI: $67 \%$ vs. $89 \% ; \mathrm{P}=0.03$ ) at univariate analysis.

Conclusions: Considering the good results based on high long-term efficacy and low morbidity after metastases surgical resection, we always recommend metastasectomy in patients with technically resectable metastases, especially in case of long DFI and reduced dimension of pulmonary lesions.
\end{abstract}

Keywords: Renal cell carcinoma (RCC); pulmonary metastasis; metastasectomy

Submitted Feb 22, 2017. Accepted for publication Apr 18, 2017.

doi: $10.21037 /$ jtd.2017.05.04

View this article at: http://dx.doi.org/10.21037/jtd.2017.05.04

\section{Introduction}

Renal cell carcinoma (RCC) represents approximately $2 \%$ of all tumors, and about $30 \%$ of patients are affected by metastatic lesions at diagnosis $(1,2)$. About $20 \%$ to $40 \%$ of patients develops a metastatic disease after nephrectomy (3) and lung is one of the sites most frequently affected by RCC metastases (second after liver) (4). Patients that receive no treatment for metastatic RCC (mRCC) have a
0-18\% 5-year survival (5). Nonsurgical therapy for mRCC has limited efficacy, with a median overall survival (OS) reported between 26.4 and 32.0 months $(6,7)$ for mRCC patients receiving several agents targeting angiogenesis or the mTOR pathway, in addition to traditional chemotherapeutic regimens and immunotherapy (8). On the contrary, the 5 -year survival rates data published in literature after pulmonary surgery for metastasectomy from $36-54 \%(9,10)$, emphasizing the role of surgery as the 
treatment that guarantees the best effectiveness in pulmonary resectable metastases, even when synchronous (11).

\section{Methods}

From January 2000 to March 2016, 27 consecutive patients underwent pulmonary metastasectomy for metastatic renal cancer at our hospital. At the moment of pulmonary metastasectomy, the primary renal cancer was controlled in all patients and there was no other metastatic site in addition to the lung. After approval of this study by our institutional review board, medical records and operative notes of all these patients were retrospectively reviewed.

Our goal was to determinate prognostic factors and outcomes in association with survival after complete pulmonary resection of RCC metastases in a subgroup of patients with isolated pulmonary metastases in a subgroup of patients with isolated pulmonary metastases from RCC.

Clinicopathologic variables were collected as follows: sex, primary cancer, histology, age at metastases outbreak (treated as a categorical variable: $\geq 60$ or $<60$ years), pulmonary metastases details [site, maximum dimension ( $\geq 2$ or $<2 \mathrm{~cm}$ ), synchronous or metachronous, number (single vs. multiple), unilateral or bilateral], disease free interval (DFI, period between the RCC diagnosis and the first metastases), neoadjuvant and adjuvant therapies, second operation for pulmonary metastasectomy. At the time of primary nephrectomy, synchronous lesions were evaluated as metastases, metachronous lesions all others. No patients received immediate adjuvant or neoadjuvant treatment systemic treatment. When new pulmonary metastases occurred (not only single but also multiple or bilateral lesions), metastasectomy was indicated in all cases when technically achievable. Subsequent surgical pulmonary resection was considered when complete metastasectomy was considered feasible, without compromising respiratory functionality of the patients. The preoperative evaluation of patients included; physical examination, routine blood tests, electrocardiography, pulmonary function test and a chest computed tomographic (CT) scan. All patients were operated on by the same surgical team through a lateral muscle-sparing or axillary thoracotomy and a selective intubation with air exclusion of the lung to be resected. A wedge resection of the lung with wide tumor-free margins was performed when feasible; a lobectomy was carried out only in case of central or big lesions. Targeted therapy, radiotherapy and traditional chemotherapy were reserved only for patients unfit for surgery or unresectable metastatic disease. The elapsed time between the first metastasectomy and death (or last follow-up) was considered as survival.

\section{Statistical analysis}

Descriptive data were expressed as mean \pm standard deviation, unless otherwise specified. Log-rank test was performed to compare survival among patients groups and survival was calculated by Kaplan-Meier analysis. Univariable analysis was used and covariates with $\mathrm{P}<0.2$ were selected for Cox multivariable analysis. Statistical analysis was performed using PASW Statistic for Windows, version 18.0 (SPSS Inc., Chicago, Illinois, USA).

\section{Results}

The characteristics of patients are reported in Table 1. In this group of 27 patients (mean age: $64.2 \pm 8.8$ years), all patients underwent prior nephrectomy and after pulmonary metastasectomy. At renal cancer diagnosis, four patients had pulmonary synchronous lesions. Ten patients underwent two lung operations: two patients for recurrence after metastasectomy and the others for contralateral disease $(\mathrm{P}<0.001)$. One patient underwent three operations for bilateral disease and recurrence on one side in a period of 172 months from the first pulmonary metastasectomy. Mean metastases size was $2.69 \pm 1.45 \mathrm{~cm}$ (range, $1-5 \mathrm{~cm}$ ), the median number of pulmonary metastases was 1 (range, $1-6$ ). In 14 patients $(51.9 \%)$ metastases were located in left lung and predominantly in lower lobes. When feasible, wedge resection was the principal type of resection performed (22 patients, $81.5 \%$ of cases). Thirty-day mortality was null. No patients underwent neoadjuvant therapy. Adjuvant traditional radio-chemotherapy or target therapy (inhibitors of VEGFR-1 and mTOR) were performed in ten patients (data available only for 18 of 27 patients) in case of unresectable metastatic progression (Table 1). The median follow-up period (FUP) was $96.27 \pm 59.70$ months from the first operation for primary renal cancer and $42.56 \pm 35.13$ months from the first pulmonary metastasectomy. Six (22.2\%) patients died for disease during FUP. Five- and 10-year OS from first pulmonary metastasectomy was $75 \%$ and $59 \%$, respectively (Figure 1). On univariate analysis, independent prognostic factors influencing survival were: dimension of pulmonary metastases $\geq 2 \mathrm{~cm}$ (3-year survival: $67 \% \mathrm{vs}$. $100 \% ; \mathrm{P}=0.014$; Figure 2) and DFI $\geq 5$ years (3-year survival: 94\% vs. 28\%; $\mathrm{P}=0.05$; Figure 3). Association between survival and type of therapy was not considered due to a 
Table 1 Clinical characteristics of patients who underwent lung metastasectomy

\begin{tabular}{ll}
\hline Characteristics & $\# 27$ patients \\
\hline Age (years) & $64.2 \pm 8.8(49-77)$ \\
Gender (male/female) & $20(74.1 \%) / 7(25.9 \%)$ \\
Histology of renal cancer & \\
Clear cell & $24(88.9 \%)$ \\
Papillary & $2(7.4 \%)$ \\
Others & $1(3.7 \%)$ \\
Number of pulmonary metastases, single/multiple & Mean: $1($ range, $1-6), 15(66.6 \%) / 12(44.4 \%)$ \\
Synchronous/metachronous metastases & $4(14.8 \%) / 23(85.2 \%)$ \\
Side (right/left) & $13(48.1 \%) / 14(51.9 \%)$ \\
Type of lung resection (wedge/lobectomy) & $22(81.5 \%) / 5(18.5 \%)$ \\
Total number of metastases per lobe (upper/middle/lower) & $16 / 5 / 19$ \\
Dimension of pulmonary metastasis (cm) & $2.69 \pm 1.45($ range, $1-5)$ \\
Adjuvant therapy (data available only for 18 patients) & \\
RT & $1(5.5 \%)$ \\
CT & $1(5.5 \%)$ \\
Target therapy & $10(55.5 \%)$ \\
\hline
\end{tabular}

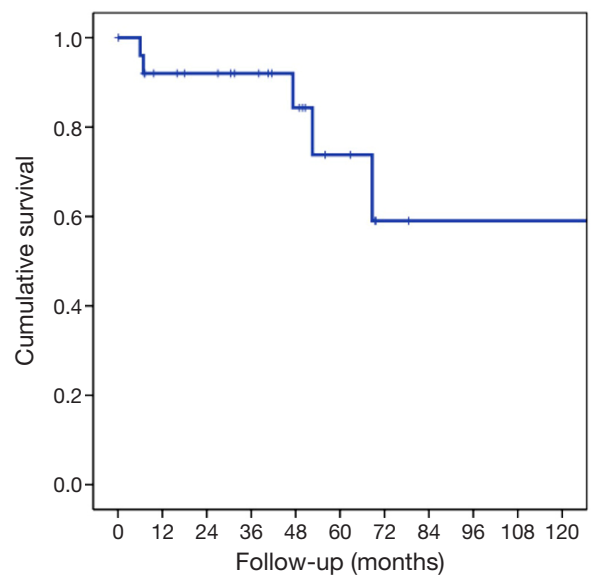

Figure 1 Overall survival from first pulmonary metastasectomy.

limited number of events. No variable was significant at multivariate analysis. The only independent prognostic factors affecting DFI was the dimension of pulmonary metastases $\geq 2 \mathrm{~cm}$ (5-year DFI: $67 \%$ vs. $89 \%$; $\mathrm{P}=0.03$ ) at univariate analysis.

\section{Discussion}

The lung is the second most affected metastatic site in

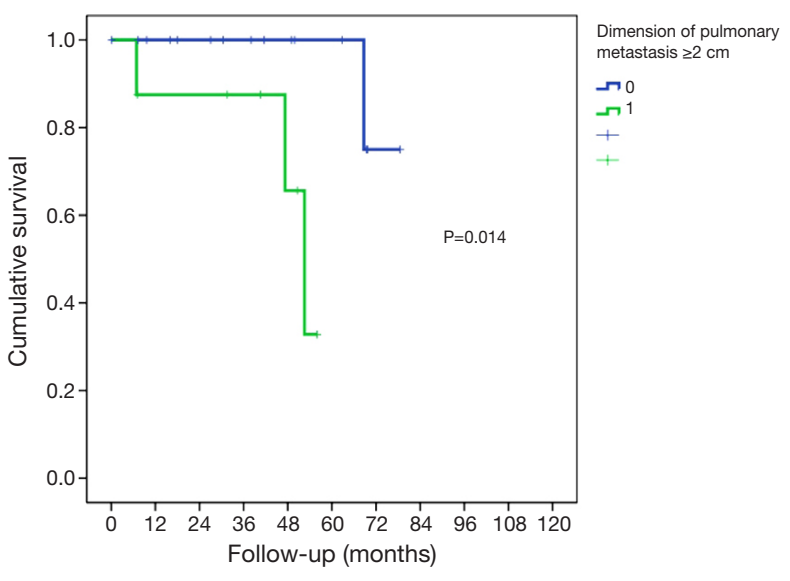

Figure 2 Log-rank test and Kaplan-Meier survival estimates according to dimension of pulmonary metastasis.

patients with RCC, immediately after the liver; thus far, many studies have been performed to analyze the role of pulmonary metastasectomy in mRCC, leading to consider pulmonary metastasectomy as the standard therapy for resectable mRCC to the lung. Amiraliev et al. (12) demonstrated a significantly higher median OS after surgical resection in comparison with immunotherapy and targeted therapy. Hence, metastasectomy of synchronous or metachronous lesions are considered the only curative treatment 


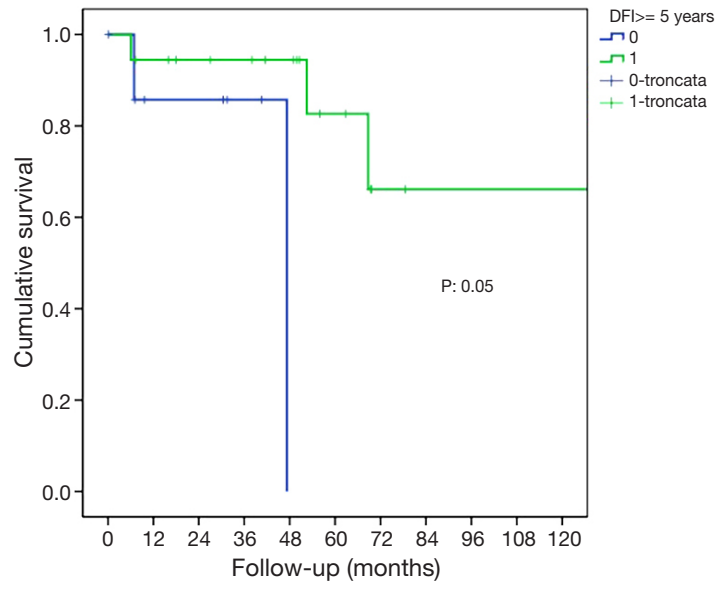

Figure 3 Log-rank test and Kaplan-Meier survival estimates according to DFI $\geq 5$ years. DFI, disease free interval.

alternative except for rare but durable responses after high dose of interleukin-2 (13). Surgical resection of RCC metastases should be performed for most sites (except for brain and bone), as guidelines of the European Association of Urology recommend (14). Resective surgery in patients with pulmonary metastases from RCC is associated with 5 -year survival rates at least $21-60 \%$ in several retrospective studies $(4,9,15-22)$ following complete metastasectomy.

In our study, we present the outcomes of 27 patients undergoing metastasectomy for isolated RCC pulmonary metastases (RCC PMs). The 5- and 10-year OS from first pulmonary resection was $75 \%$ and $59 \%$, respectively, which is encouraging and unawares better than that reported in previous studies (23-25). In 2008, Chen et al. (4) showed a 5 - and 10 -year OS rate of $83.3 \%$ and $41.7 \%$. While 3 - and 5 -year disease-free survival rate was $35.0 \%$ and $17.5 \%$; this institutional experience was limited to eight highly selected patients with RCC PMs underwent complete pulmonary resection. Large, non-comparative previous case series reported 5-year survival of $37-54 \%$ for radically resected isolated metastases or oligo metastatic pulmonary disease (19,25-29). The reasons of our remarkable 5- and 10-year survival remain unclear, but we can hypothesize that the strict selection criteria influenced results. Metastasectomy was performed in patients without local residual disease or local recurrence, multi-organ metastases and a good performance status. Additionally, surgical techniques and recent progress in perioperative management allow better prognoses. In our experience only 4 patients (14.8\%) had pulmonary synchronous lesions at RCC diagnosis and $63 \%$ of patients underwent surgery for single pulmonary metastases, more than reported in literature (47-56\%) $(19,23,24)$.

No patients included in our experience underwent alternative therapy or non-complete resection for diagnosis. Preoperative CT scan was carefully analyzed in order to evaluate information about resectability of specific nodules and predict incomplete resection because partial resection influenced significantly the 5-year survival rate as reported in literature: $44 \%$ for complete resection, $14 \%$ for incomplete resection and $11 \%$ for no surgical resection (22).

Univariate analysis of our data showed that longer DFI and reduced dimension of pulmonary lesion size is relevant for survival of completely resected patients. Patients with DFI $\geq 5$ years and dimension of pulmonary metastases $<2 \mathrm{~cm}$ had the best prognosis.

A short DFI following nephrectomy or the presence of synchronous metastases has already been associated with poor outcome $(9,19,25,29)$, as the size of lung metastases $(19,23,26)$, while a longer DFI after nephrectomy is considered as a positive prognostic factor $(9,22)$. Meimarakis et al. (30) reported better OS in patients with metachronous disease compared with patients with synchronous disease at the moment of diagnosis \{median OS 54.0 months [95\% confidence interval (CI), 30.3-77.7 months] and 28.2 months (95\% CI, 18.1-38.4 months) respectively; $\mathrm{P}=018\}$. Histological subtype of RCC did not influence the OS benefit. For patients with DFI $<24$ months, the median survival was 30.6 months (95\% CI, 22.3-38.9 months) while for patients with DFI $>24$ months the median survival was 66.6 months (95\% CI, 32.3-100.8 months; $\mathrm{P}=010$ ). A cutoff value for DFI is identified in several studies and it's ranged between 20 and 36 months for significantly improved survival. It can be asserted that longer DFI may be associated to a less aggressive RCC. Non-comparative studies showed that the RCC dynamic might be more important than any intervention. Long metachronous intervals with reiterative surgery (22) and low tumor grade (31) are associated with better OS. Patients with oligo metastatic disease and long metachronous intervals are more suitable for surgery than patients with high-volume lesions and rapid tumor progression.

Tumor size cutoff, as an independent favorable prognostic factor, is still controversial $(19,23,26,30)$ but in our report, $2 \mathrm{~cm}$ was a significant cutoff value as in other previous studies $(24,32)$.

The main strength of this paper is its rigorous methodology policy in the patient's selection. We strictly evaluated the outcome of patients affected by isolated lung 
metastases, with curative intention at metastasectomy. Patients were not affected by isolated lung metastases in other organs. However, there were some limitations. Our study was retrospective and involved a quite small number of patients. In this report we did not study lymph node metastases, as the main issue was on pulmonary metastases and resection. Many patients continued therapy at other institutions, thus systemic treatment could not be recorded. Nevertheless our findings denote that patients underwent complete resection have good long term survival and metastasectomy should be attempted if complete resection can be performed, especially in case of long DFI and reduced dimension of pulmonary lesions. Despite the presence of synchronous metastases get prognosis worse, it does not exclude surgery if radical resection can be performed.

\section{Conclusions}

Considering the good results based on high long-term efficacy and low morbidity after metastases surgical resection, we always recommend metastasectomy in patients with technically resectable metastases, especially in case of long DFI and reduced dimension of pulmonary lesions.

\section{Acknowledgements}

None.

\section{Footnote}

Conflicts of Interest: The authors have no conflicts of interest to declare.

Ethical Statement: The study was approved by the Institutional Review Board of Catholic University of Sacred Hearth.

\section{References}

1. Pantuck AJ, Zisman A, Belldegrun AS. The changing natural history of renal cell carcinoma. J Urol 2001;166:1611-23.

2. Kattan MW, Reuter V, Motzer RJ, et al. A postoperative prognostic nomogram for renal cell carcinoma. J Urol 2001;166:63-7.

3. Ruutu M, Bono P, Taari K. Resection of renal cell cancer metastases: where do we stand in 2008? Eur Urol Suppl
2008;7:436-42.

4. Chen F, Fujinaga T, Shoji T, et al. Pulmonary resection for metastasis from renal cell carcinoma. Interact Cardiovasc Thorac Surg 2008;7:825-8.

5. Rosenberg SA, Lotze MT, Yang JC, et al. Combination therapy with interleukin-2 and alpha-interferon for the treatment of patients with advanced cancer. J Clin Oncol 1989;7:1863-74.

6. Motzer RJ, Hutson TE, Tomczak P, et al. Overall survival and updated results for sunitinib compared with interferon alfa in patients with metastatic renal cell carcinoma. J Clin Oncol 2009;27:3584-90.

7. Motzer RJ, Barrios CH, Kim TM, et al. Phase II randomized trial comparing sequential first-line everolimus and second-line sunitinib versus first-line sunitinib and second-line everolimus in patients with metastatic renal cell carcinoma. J Clin Oncol 2014;32:2765-72.

8. Sella A, Logothetis CJ, Fitz K, et al. Phase II study of interferon-alpha and chemotherapy (5-fluorouracil and mitomycin C) in metastatic renal cell cancer. J Urol 1992;147:573-7.

9. Hofmann HS, Neef H, Krohe K, et al. Prognostic factors and survival after pulmonary resection of metastatic renal cell carcinoma. Eur Urol 2005;48:77-81; discussion 81-2.

10. Barney JD, Churchill EJ. Adenocarcinoma of the kidney with metastasis to the lung. J Urol 1939;42:269-76.

11. Ljungberg B, Cowan NC, Hanbury DC, et al. EAU guidelines on renal cell carcinoma: the 2010 update. Eur Urol 2010;58:398-406.

12. Amiraliev A, Pikin O, Alekseev B, et al. Treatment strategy in patients with pulmonary metastases of renal cell cancer. Interact CardioVasc Thorac Surg 2012;15 suppl 1:SXIII-F068.

13. Heng DY, Xie W, Regan MM, et al. External validation and comparison with other models of the International Metastatic Renal-Cell Carcinoma Database Consortium prognostic model: a population-based study. Lancet Oncol 2013;14:141-8.

14. Ljungberg B, Bensalah K, Canfield S, et al. EAU guidelines on renal cell carcinoma: 2014 update. Eur Urol 2015;67:913-24.

15. Friedel G, Hürtgen $M$, Penzenstadler $M$, et al. Resection of pulmonary metastases from renal cell carcinoma. Anticancer Res 1999;19:1593-6.

16. Dernevik L, Berggren H, Larsson S, et al. Surgical removal of pulmonary metastases from renal cell carcinoma. Scand J Urol Nephrol 1985;19:133-7.

17. Cerfolio RJ, Allen MS, Deschamps C, et al. Pulmonary 
resection of metastatic renal cell carcinoma. Ann Thorac Surg 1994;57:339-44.

18. Pogrebniak HW, Haas G, Linehan WM, et al. Renal cell carcinoma: resection of solitary and multiple metastases. Ann Thorac Surg 1992;54:33-8.

19. Piltz S, Meimarakis G, Wichmann MW, et al. Long-term results after pulmonary resection of renal cell carcinoma metastases. Ann Thorac Surg 2002;73:1082-7.

20. Dineen MK, Pastore RD, Emrich LJ, et al. Results of surgical treatment of renal cell carcinoma with solitary metastasis. J Urol 1988;140:277-9.

21. Fourquier P, Regnard JF, Rea S, et al. Lung metastases of renal cell carcinoma: results of surgical resection. Eur J Cardiothorac Surg 1997;11:17-21.

22. Kavolius JP, Mastorakos DP, Pavlovich C, et al. Resection of metastatic renal cell carcinoma. J Clin Oncol 1998;16:2261-6.

23. Murthy SC, Kim K, Rice TW, et al. Can we predict longterm survival after pulmonary metastasectomy for renal cell carcinoma? Ann Thorac Surg 2005;79:996-1003.

24. Kawashima A, Nakayama M, Oka D, et al. Pulmonary metastasectomy in patients with renal cell carcinoma: a single-institution experience. Int J Clin Oncol 2011;16:660-5.

25. Kanzaki R, Higashiyama M, Fujiwara A, et al. Long-term results of surgical resection for pulmonary metastasis

Cite this article as: Meacci E, Nachira D, Congedo MT, Porziella V, Chiappetta M, Ferretti G, Iaffaldano A, Ciavarella LP, Margaritora S. Lung metastasectomy following kidney tumors: outcomes and prognostic factors from a single-center experience. J Thorac Dis 2017;9(Suppl 12):S1267-S1272. doi: $10.21037 /$ jtd.2017.05.04 from renal cell carcinoma: a 25-year single-institution experience. Eur J Cardiothorac Surg 2011;39:167-72.

26. Assouad J, Petkova B, Berna P, et al. Renal cell carcinoma lung metastases surgery: pathologic findings and prognostic factors. Ann Thorac Surg 2007;84:1114-20.

27. Marulli G, Sartori F, Bassi PF, et al. Long-term results of surgical management of pulmonary metastases from renal cell carcinoma. Thorac Cardiovasc Surg 2006;54:544-7.

28. Mineo TC, Ambrogi V, Tonini G, et al. Pulmonary metastasectomy: might the type of resection affect survival? J Surg Oncol 2001;76:47-52.

29. Pfannschmidt J, Hoffmann H, Muley T, et al. Prognostic factors for survival after pulmonary resection of metastatic renal cell carcinoma. Ann Thorac Surg 2002;74:1653-7.

30. Meimarakis G, Angele M, Staehler M, et al. Evaluation of a new prognostic score (Munich score) to predict longterm survival after resection of pulmonary renal cell carcinoma metastases. Am J Surg 2011;202:158-67.

31. Kierney PC, Van Heerden JA, Segura JW, et al. Surgeon's role in the management of solitary renal cell carcinoma metastases occurring subsequent to initial curative nephrectomy: an institutional review. Ann Surg Oncol 1994;1:345-52.

32. Dabestani S, Marconi L, Hofmann F, et al. Local treatments for metastases of renal cell carcinoma: a systematic review. Lancet Oncol 2014;15:e549-61. 